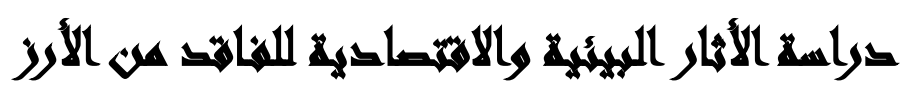

[19]

أحمد فؤاد مندور (')- سهام أحمد عبد الحميد(؟)- آية محمود سيد سالم

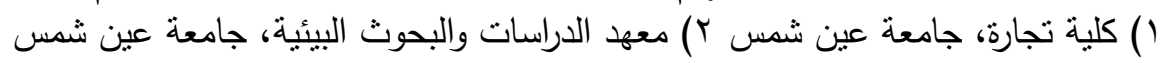

\section{المستحلت}

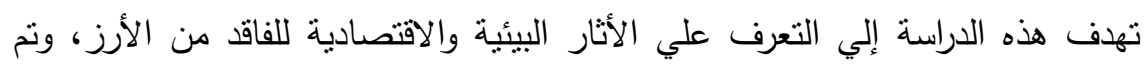

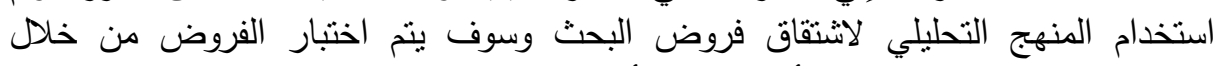

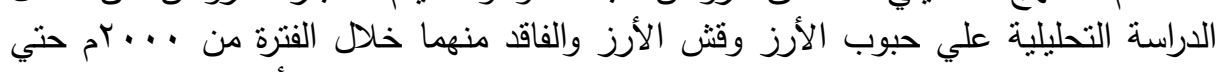

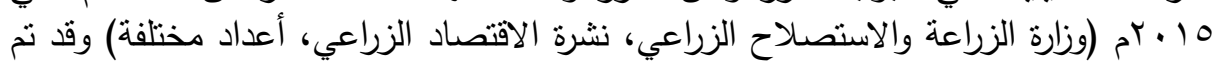

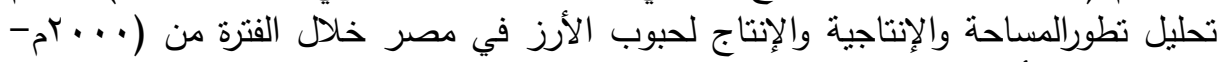
10

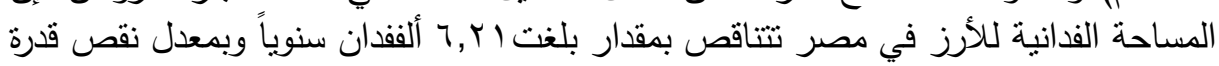

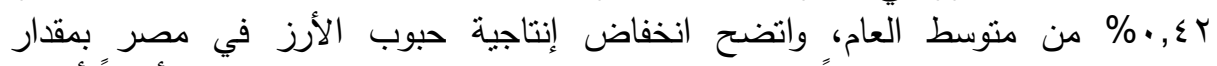

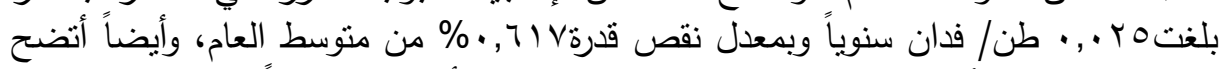

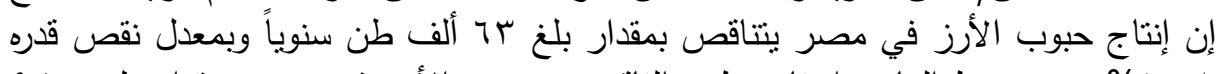

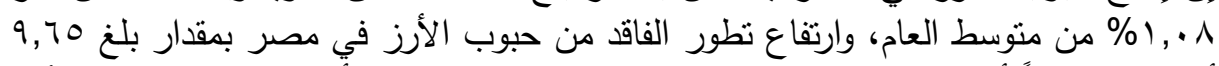

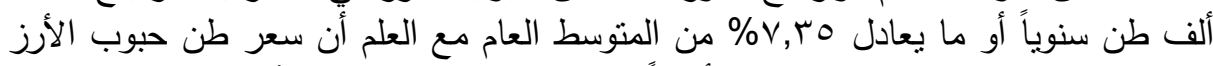

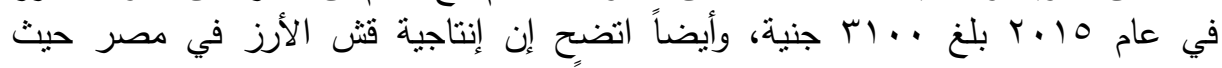

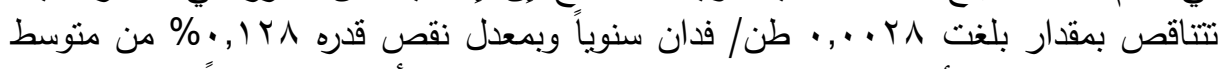

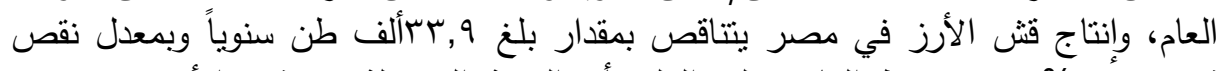

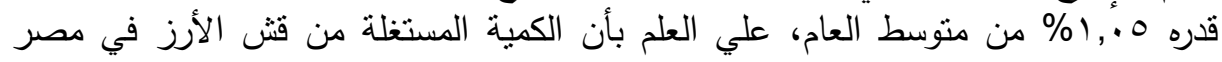

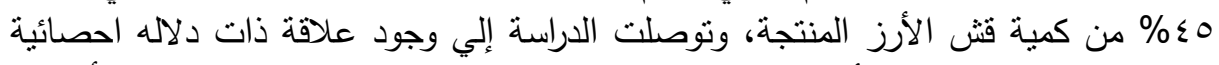

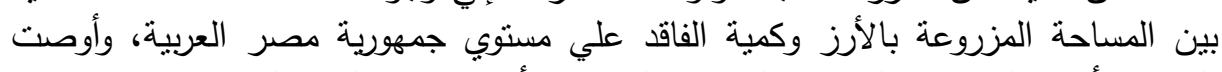

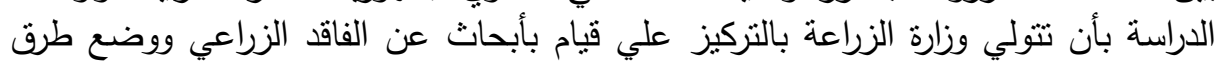

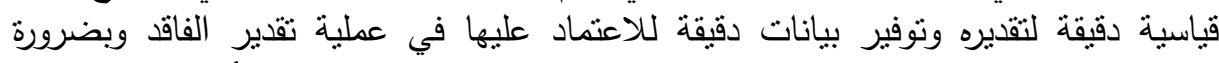

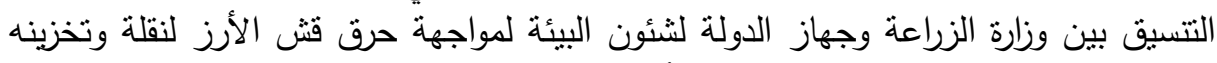

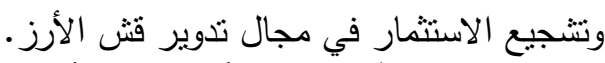

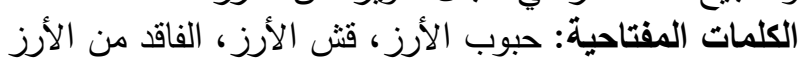




\section{xasadl}

أصبح الاهتمام الحالي بالمحافظة علي البيئة وتجنب مسبيات تلوث وإعادة صيانه وترميم البيئة ذا أهميه كبيرة لمختلف فئات المجتمع حيث أن التوجه نحو حمايه البيئة ومحاوله منع التدهور السريع البيئي الناجم عن التلوث محط اهتمام المجتمع لأن الإهدار بصفه عامه والموارد الزراعية بصفه خاصه في نزايد مستمر وقد تزايدت الأهمية العلمية لدراسة المشكلة ندرة الموارد الزراعية بسبب النأثنر السلبي الناتج من الأنشطة البشرية علي الموارد الزراعية

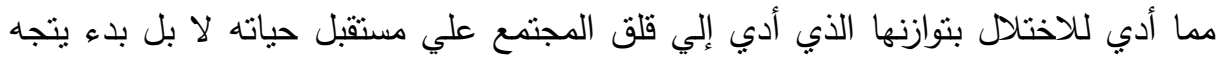
نحو حمايه الموارد الطبيعية بصفه عامه الموارد الزراعية بصفه خاصه ويبذل قصاري جهذه في محاوله تقليل المخاطر الناتجة من الأنشطة البشرية التي أدت إلي تدهور الموارد المائية

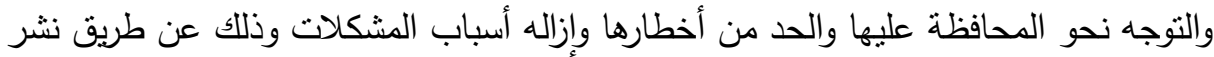
الوعي البيئي بين كافه شرائح المجتمع حيث أصبحت مسئوليه اجتماعية للحفاظ علي الموارد الطبيعية بصفه عامه والموارد الزراعية بصفه خاصة.

يعتبر الفاقد في الحاصلات الزراعية مشكله ليس محليه ولكن عالميه ولكن تصبح أكثر وضوحاً في الدول النامية نتيجة لطبيعة الظروف الاجتماعية الاقتصادية السائدة وعدم توفر

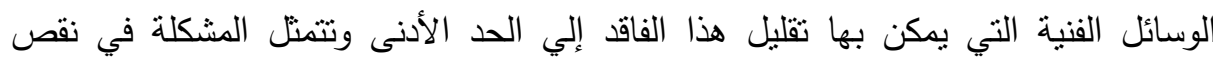
كميات من الغذاء مما يزيد من حجم المشكلة اقتصادياً وبيئياً ولهذا تصبح مشكله معقدة.

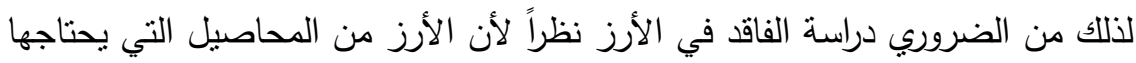

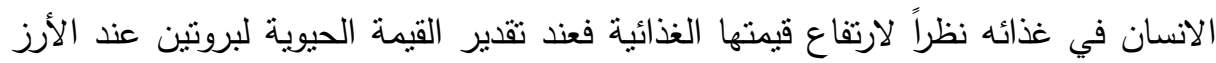
وجد أنها مرتفعة بالنسبة لأنواع الأخرى من الحبوب ويعتبر محصول الأرز أحد محاصيل

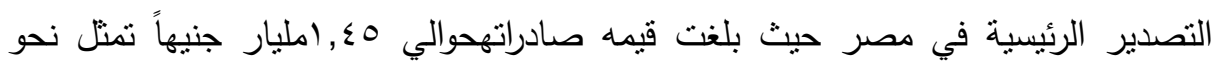

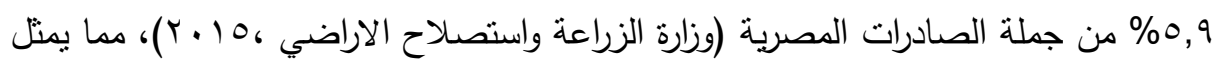
مصدراً هاماً لحصيلة النق الأجنبي. 
عليه فإن الوعي بالأثار البيئية والاقتصادية للفاقد في محصول الأرز ونواتجه الثانوية سوف يساعد في التعرف علي الأضرار التي تؤثز علي محصول الأرز بل أيضاً علي البيئة

\section{Anan}

تتحصر مشكله البحث بصفه أساسيه في وجود نسبه مرتفعة للفاقد بصفه عامه والأرز بصفه خاصه وتعتبر أحد المشكلات التي تواجه بعض دول العالم نظراً لأثارها الاقتصادية

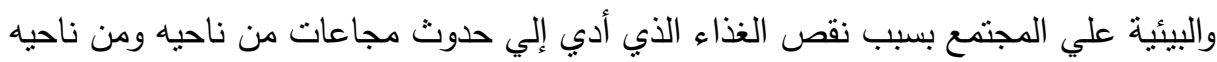

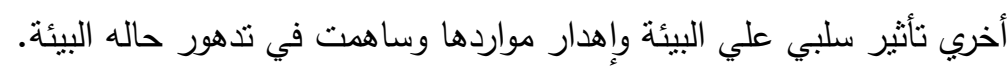

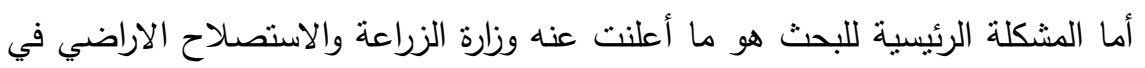

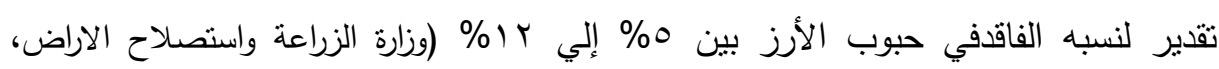
$(r \cdot 10$ وتكمن أحد المشاكل هو أن ب0\% من قش الأرز (وزارة الدولة لشئون البيئة، 10 • ب) غير مستغل ويؤدي ذلك إلي حرقه وحدوث أزمة تلوث الهواء، حيث تشكل عوادم الهن السيارات نسبة

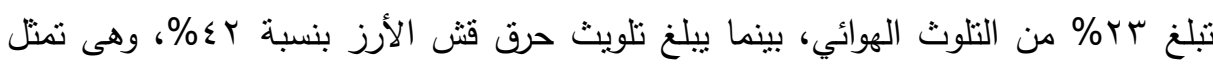

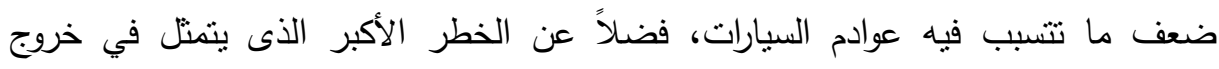
جزيئات دقيقة أثناء عملية الحرق تتسبب في حدوث التهاب في العين وأمراض الحساسية والتهاب الجيوب الأنفية والحنجرة، ما يمثل نحو خمسة أضعاف معدلات دئه حدوثه في الظروف

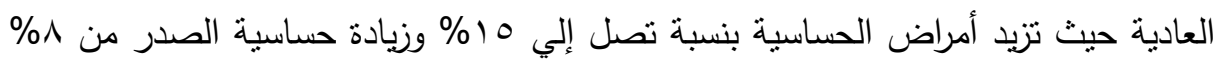

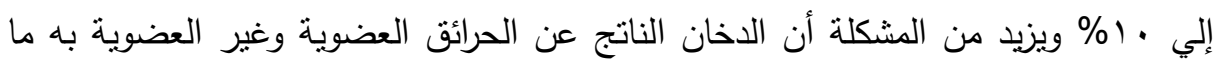
يقرب من 11 مادة مسرطنة، طبقاً لإحصائيات البنك الدوليتخسر مصر سنوياً . r مليار جنيه نتيجة حرق القش الأرز. 
مجلة العلوم البيئية

معهد الدراسات والبحوث البيئية - جامعة عين شمس لبهن

\section{أسئلا الهمهي}

أ) إن أسئلة البحث تتركز في الاجابة عن السؤال الرئيسي الآتي:

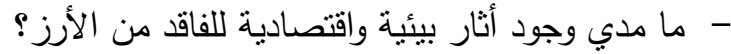

ب) ويستتد من هذا السؤال الرئيسي السابق عدة أسئلة فرعية منها:

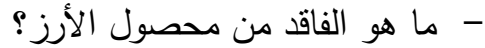
- هل هناك أثنار اقتصادية للفاقد من حبوب الأرز؟ - هل هناك أثار بيئية لعدم استخدام فش الأرز؟

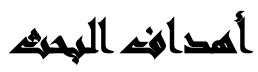

تهفف الدراسة بصفة أساسية إلي إلقاء الضوء علي الهدف الرئيسي هو دراسة الأثار

البيائية والاقتصادية للفاقد من الأرز . وتتحقق هذه الاراسة عن طريق الأهداف الفرعية التالية ومنها:

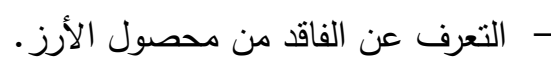

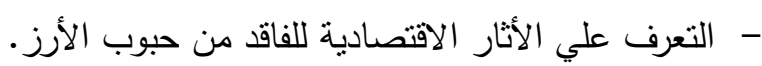
- التعرف علي الأثار البيئية لعدم استخدام قش الأرز.

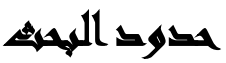

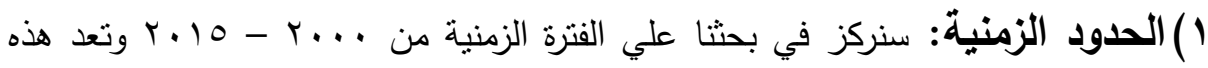

الفترة ستكون كافيه لأجراء الدراسة التحليلية المطلوبة للوقوف علي طبيعة المتغيرات واستخلاص دلالتها.

Y) الحدود المكانية: جمهورية مصر العربية لدراسة النطورات السريعة التي نستجد في

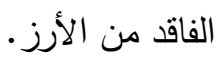


r) التركيز علي العلاقة بين الأثار البيئية والاقتصادية للفاقد من الأرز.

\section{هزوضر الهمهي}

() توجد علاقة ارتباط ذات دلالة احصائية بين المساحة المزروعة بالأرز وكمية الفاقد علي

$$
\text { مستوي جمهورية مصر العربية. }
$$

r آلا توجد علاقة ارتباط ذات دلالة احصائية بين الإنتاجية الفدانية وكمية الفاقد علي مستوي

$$
\text { جمهورية مصر العربية. }
$$

r) لا توجد علاقة ارتباط ذات دلالة احصائية بين كمية الإنتاج من الأرز وكمية الفاقد علي مستوي جمهورية مصر العربية.

\section{منهمج الهيهA}

تعتد هذه الدراسة علي استخدام الدنهج الوصفي النحليلي العلمي الذي بساعد علي

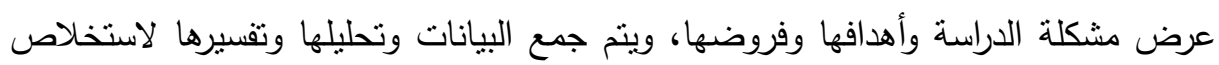

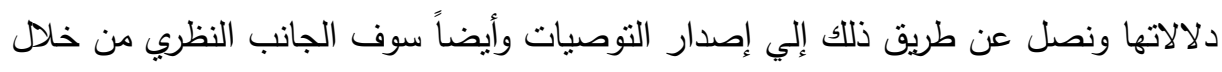

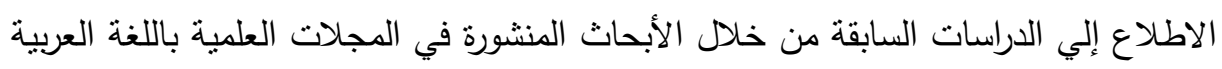

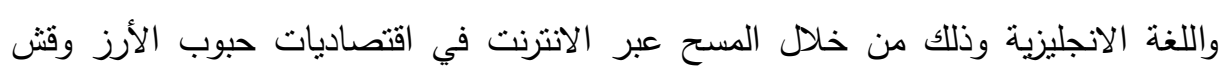
الأرز والفاقد منهما والأثار البيئية لهما.

\section{أهمية المهبه}

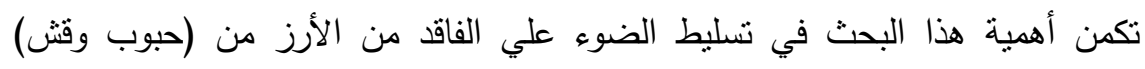

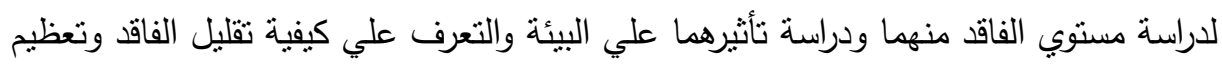

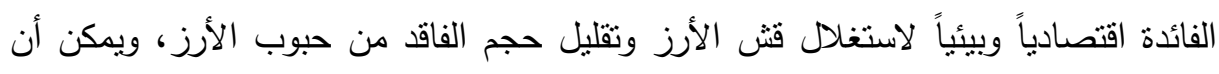

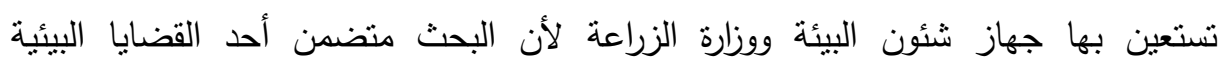

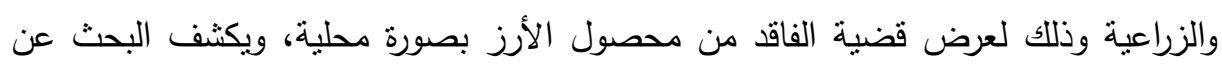

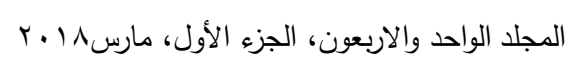


أهمية دراسة الفاقد من محصول الأرز والتطورات السريعة التي تستجد في الفاقد من محصول الأرز .

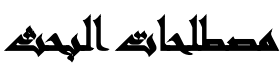

\section{(المهاهيهر)}

أولاً: تعريف الفاقد الزراعي: يختلف مفهوم الفاقد باختلاف الهدف من الدراسة سواء من الناحية الفنية أو الاقتصادية، لذلك فإن بعض هذه المفاهيم يشويها العديد من التداخلات، ومن باتل

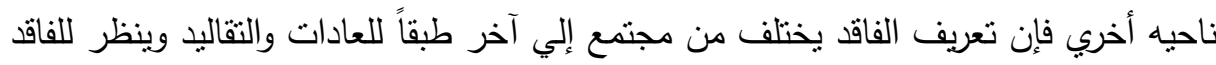
علي أنه الخسارة (LOSS) ويقصد به النقص في كمية الغداء المتاح للاستهلاك ،وكذللك لفظ التلف (Damage) والذي يعبر عن الفساد الفيزيقي ويصعب قياسه بدقة، وكما أنه هناك لفظ بهاء

$$
\text { (Waste) }
$$
ثانياً: مفهوم النواتج الثانوية: تعرف بأنها جميع النواتج الثانوية الناتجة من الانتاج النباتي كالنواتج الثنانوية للنباتات كالعروش والفروع والاوراق والسيقان والثمار غير المسوقة

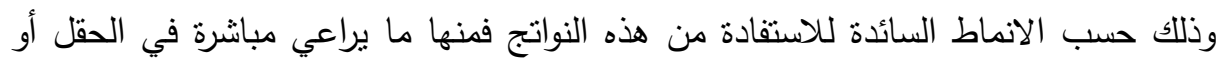

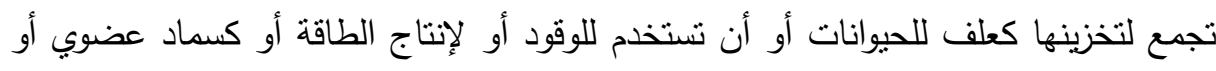

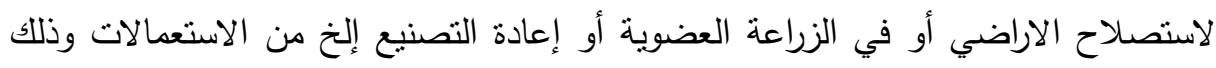
تبعاً لمصدرها وخصائصها الفيزيائية والكيميائية.

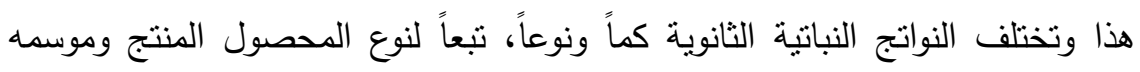
وكيفية جمعه وتسويقه، إضافة للمخلفات الناتجة عن التصنيع الوسيط للمنتجات الزراعية ونية

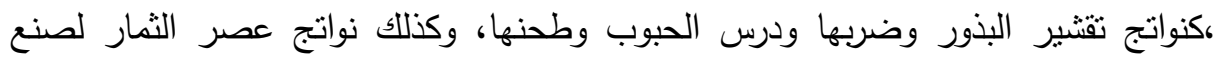

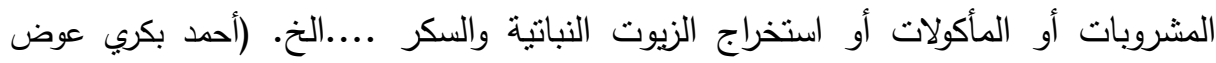


ثالثاً: مخلفات النباتية من محصول الأرز:

( ) قش الأرز: قش الأرز يعتبر أحد النواتج الهامة لمحصول الأرز وتقدر الكمية الناتجة منه

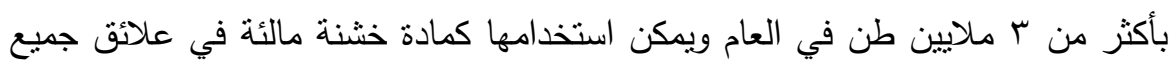

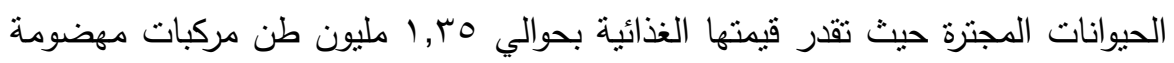

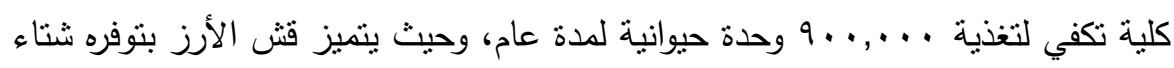
في حين تقل أنبان القمح والفول والبرسيم ويستخدم لتغذية الحيوانات كبديل لتلك المواد بنفس المقررات الغذائية ولأنه يتميز بانخفاض سعره يساعد ذللك علي تقليل نكاليف الانتاج

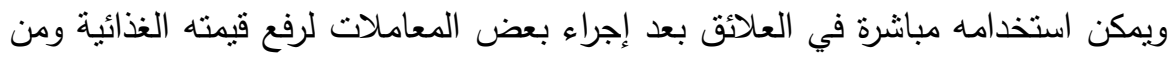

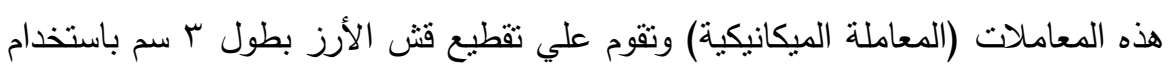

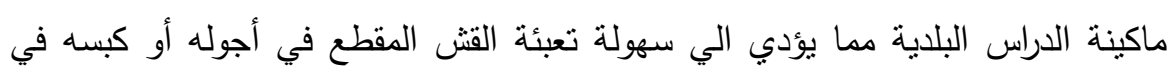

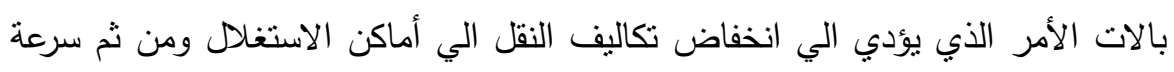

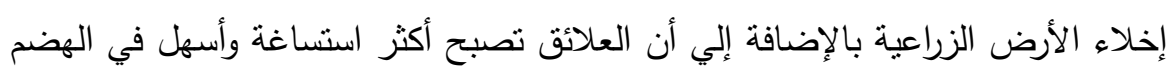
مما يؤدي إلي ارتفاع انتاجية الحيوان من لحم أو لبن، وفي حالة معاملة القش بغاز

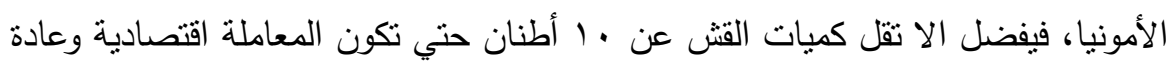

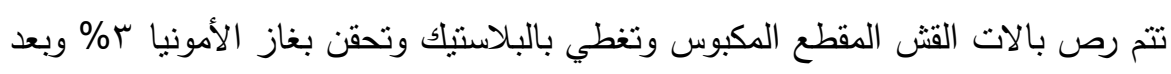

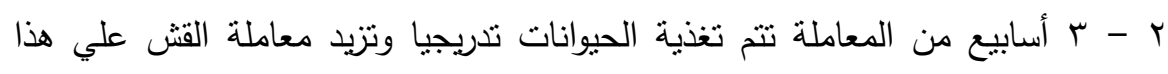

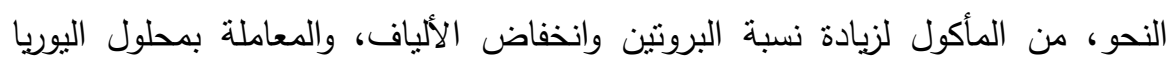

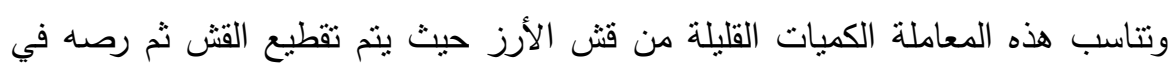

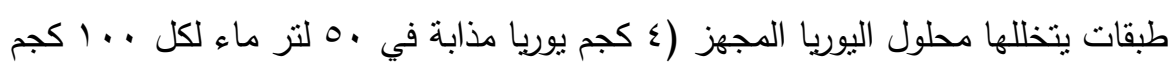

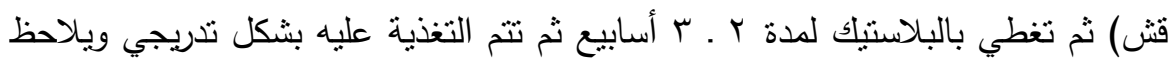

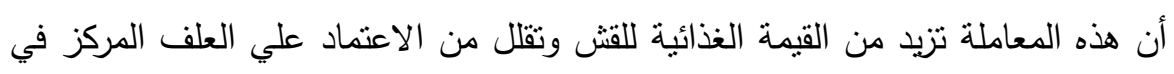
العلائق الأمر الذي يقلل من تكاليف الإنتاج. 


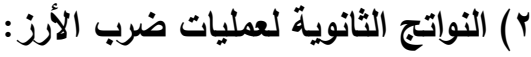

أ) رجيع الكون (نخالة الأرذ): تمنل الأغلفة الداخلية لحبوب الأرز ويمثل رجيع الكون (الأرز) 9,7\% من وزن الحبة وبالتالي تقدر الكمية السنوية الناتجة بعدة مئات الألوف من الأبع

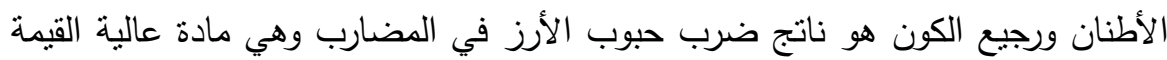

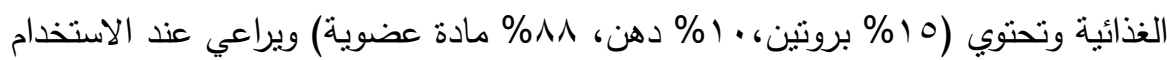

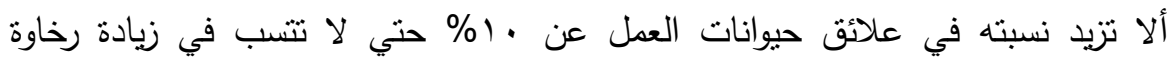
العضلات وألا تزيد النسبة في علف مانثية اللبن عن التلث حتي لا تزداد سيولة دهن الزبد

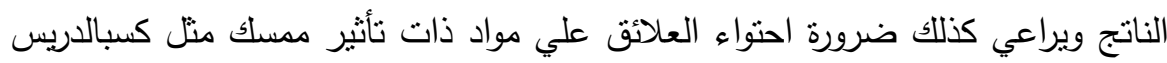
أو بذرة القطن وذللك لارتفاع نسب الزيت في الرجيع التي تحدث نأثيرا مليئا علي الجهاز

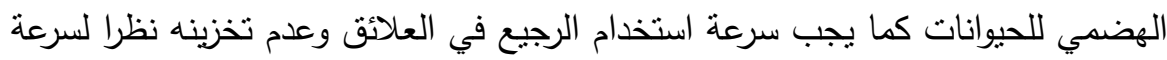
فساده وتزنخه وتكنله (بسبب محتواه من الزيت) مما يجعله صالح للتغذية عليه.(وزارة الدولة

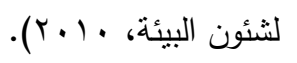

ب) الرجيع البلاي: يتخلف من ضرب الأرز الثعير في المضارب البلدية أو الفركات ويمنل

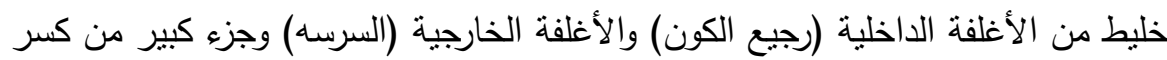

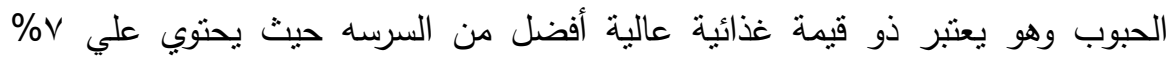

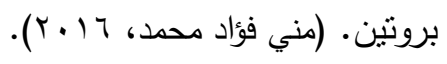

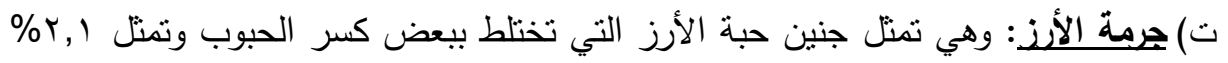

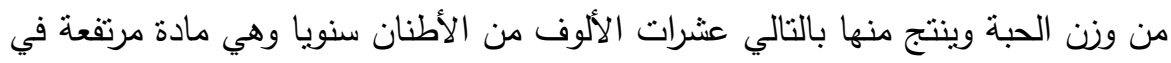

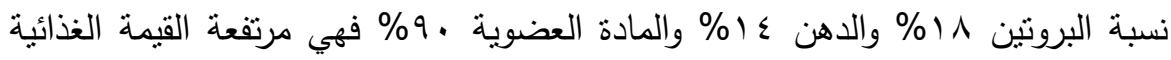
ويراعي عدم تخزينها وذلك لسرعة تلفها بسبب ارتفاع نسبة الزيت بها وهناك كسب الجرمة

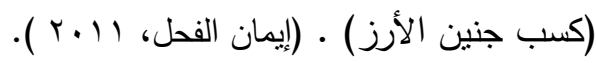


ث)مخلفات صناعة نشا الأرذ: تمثل هذه المخلفات مجموعة نواتج المختلفة من صناعة النشا

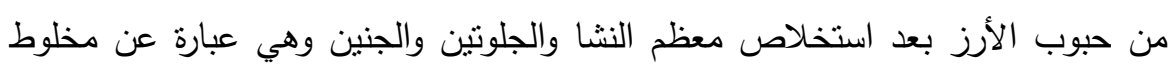

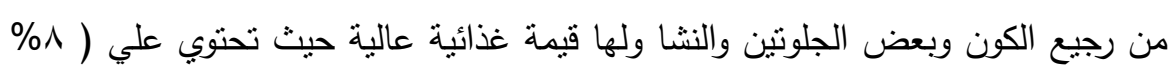

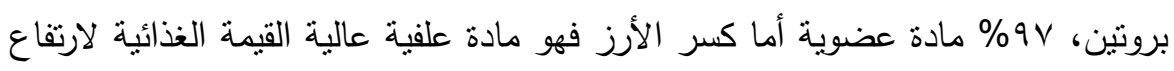

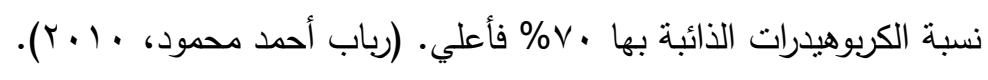

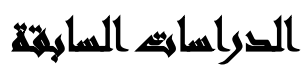

ذكر عبد الباري وآخرون إن الفقد الكلى في محصول الأرز في مصر نتيجة لعمليات

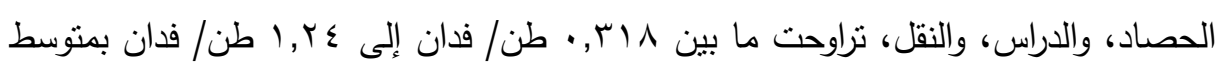

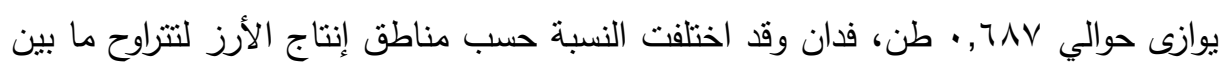

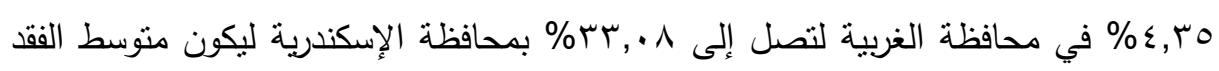

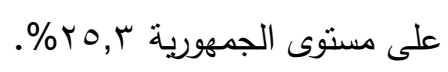

قد استخدم Abd.el.Motalb نوعية من الآت الحصاد الآلي ووجد إن نسبة الفقد عند

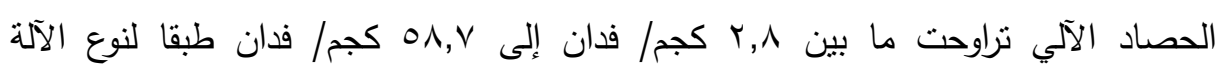

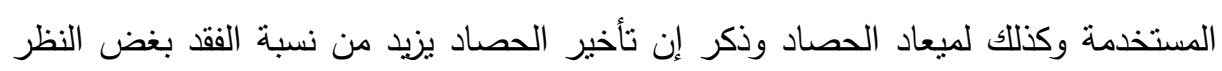
عن نوع الآلة المستخدمة. ذكر Ramos إن استخدام القرصة هي طريقة سائدة للاراس في الدلتا في مصر ( وهى الدي

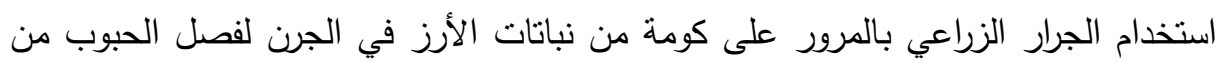

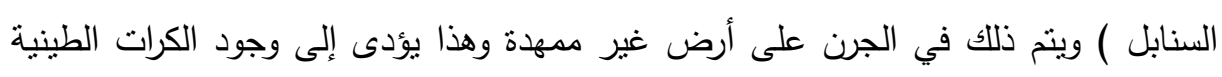

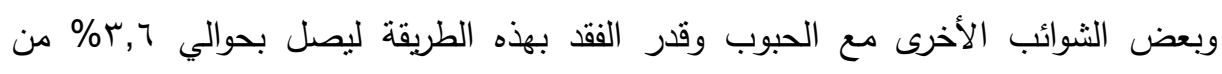
المحصول الناتج وذلك بخلاف حدوث النتققات وارتفاع نسبة الكسر في الحبوب أثناء عملية التبييض.

قدر Chazy الفاقد في الحصاد الآلي في الصنف جيزة r البنحو \%,0,\% ويرجع هذا الفاقد إلى سنابل نركت في الحقل بنسبة كبيرة وقد يرجع هذا الفقد إلى الرقاد كما يتأثر أيضا بسرعة آلة الحصاد المستخدمة.

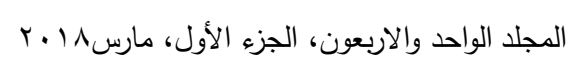


أوضحت دراسة جهادعن "التقدير الاقتصادي للفاقد التسويقي لمحصول الأرز في محافظه دمياط" استهدفت نقدير الفاقد التسويقي من مرحلة الحصاد حتي مرحله التخزين،

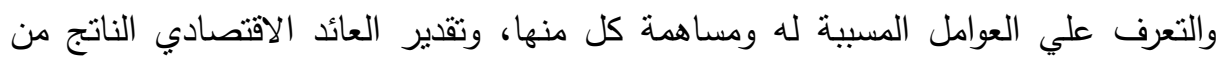

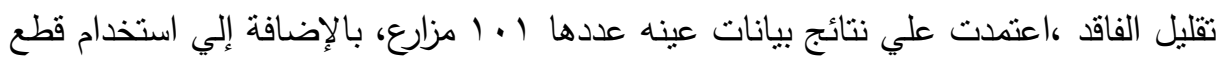

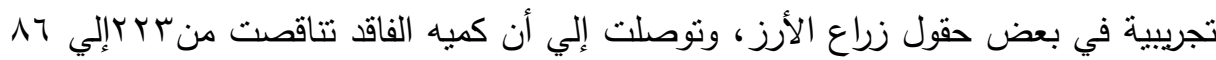
كجم للفدان عند زراعة مساحات أكبر منو أفدنه، وذللك بسبب سماح المساحات الكبيرة

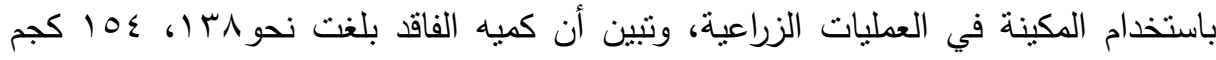

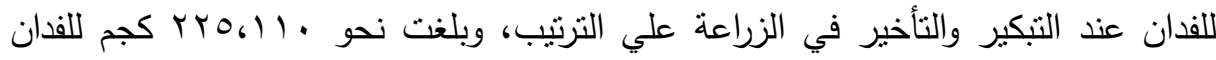

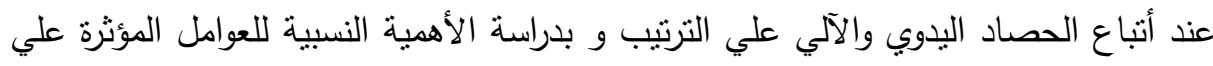

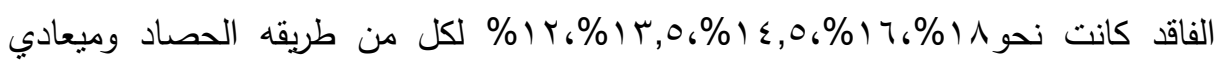
الزراعة والحصاد وتجفيف وتخزين المحصول علي الترنيب، وتبين أن منوسط كميه الفاقد بلغ

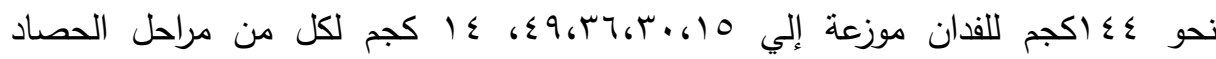
والتجفيف والنقل والدراس والتعبئة علي الترتيب، وبضرب هذا الفاقد في المساحة المزروعة

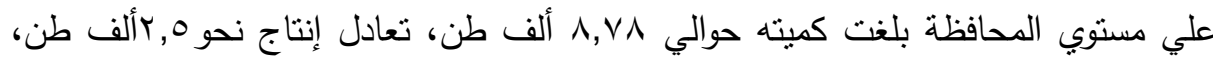

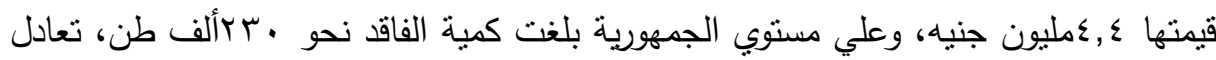

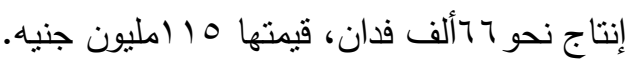
قام كلاً العراقي وآخرون بعمل بحث عن"التحليل الاحصائي للفاقد ما بعد الحصاد

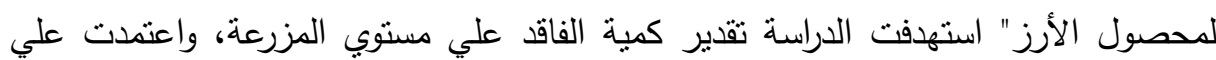

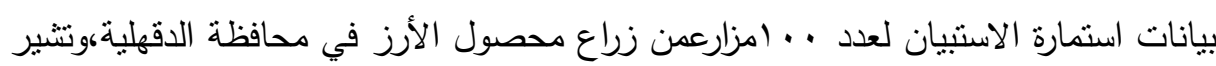

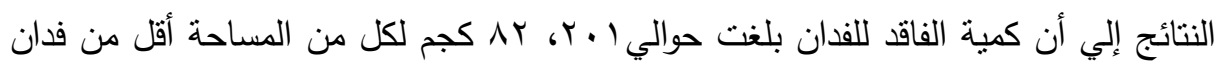
والمساحة أكثر من بأفدنة علي الترتيب ،أي أن العلاقة عكسية بين الفاقد والمساحة، وأن

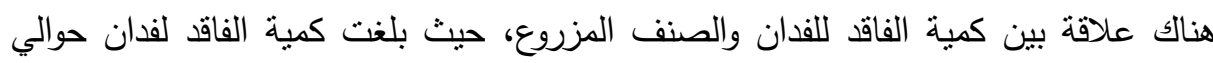

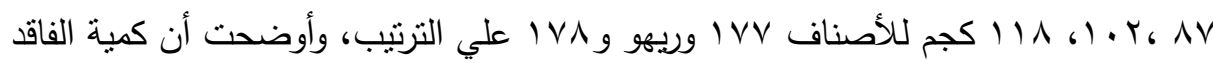




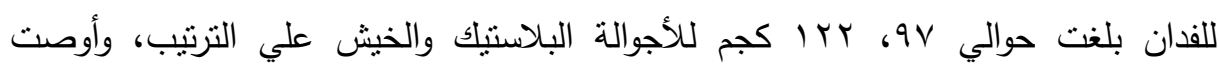

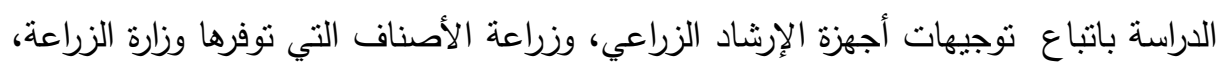

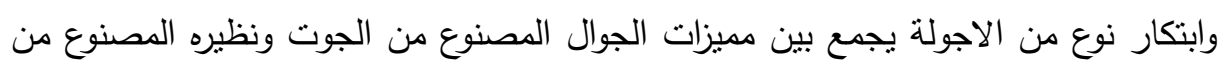
البلاستيك ويكون سعره في متتاول المزارعين.

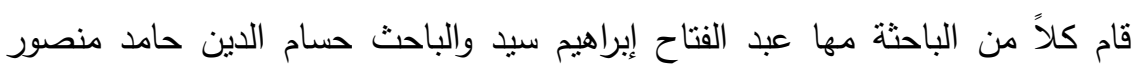

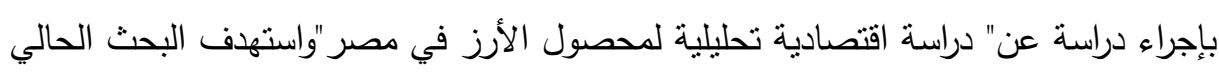

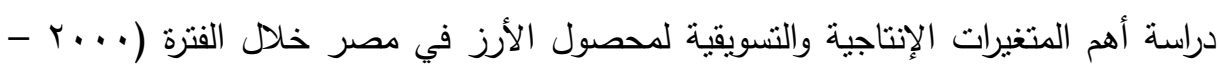

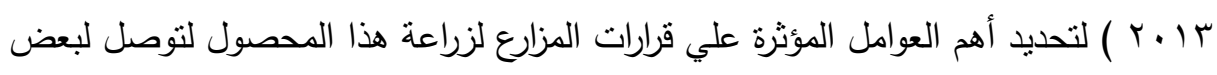

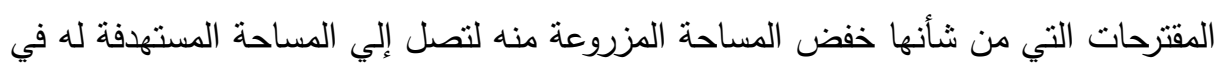
التركيب المحصول التاثيري، وقد أسفرت نتائج التحليل الإحصائي والاقتصادي عن النتائج الثالية:شهدت المساحة المزروعة والاتتاجية الفدانيه والإنتاج الكلي خلال فترة الدراسة استقرار نسبياً لهذه المتغيرات لعدم معنويه التتاقص في المساحة المزروعة والإنتاج الكلي وعدم معنويه الزيادة في الانتاجية الفدانيه، وتعتبر محافظات الدقهلية وكفر الثيخ والثرقية والبحيرة والغربية

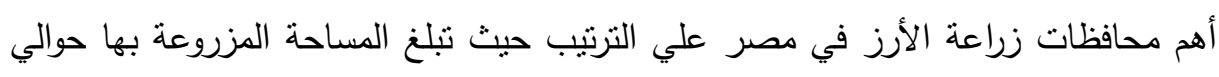

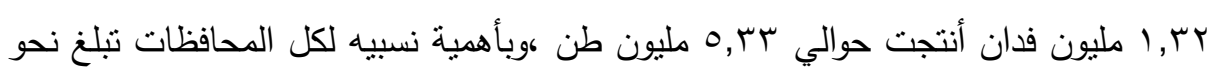

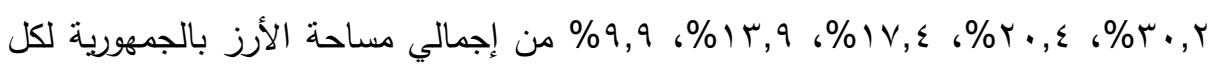

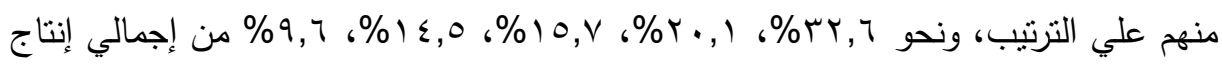

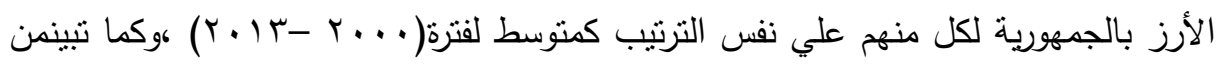

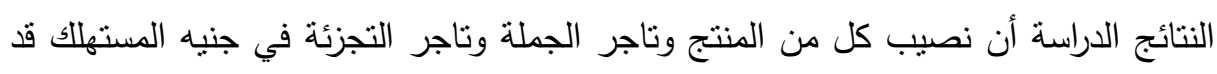

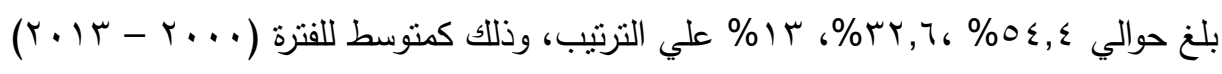

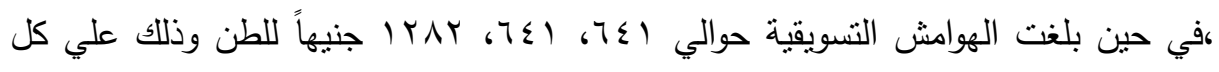
من مسنوي ناجر الجملة والمنتج ،وتاجر التجزئة وتاجر الجملة، وتاجر التجزئة والمنتج علي لئي الترتيب وذللك كمتوسط للفترة السابق ذكرها. 
أما قامت مروة بدراسة عن الأثار الاقتصادية والبيئية للإدارة المتكاملة لمخلفات قش الأرز وحطب الذرة بالنطبيق علي محافظة الثرقية ويهذف البحث إلي توضيح المشاكل البيئية والاقتصادية المترتبة من استغلال الخاطئ للمخلفات الزراعية وتتاول طرق ووسائل إعادة تدوبر المخلفات الزراعية ودورها في التتمية الاقتصادية وتوضيح الاستراتيجية متكاملة لإدارة المخلفات الزراعية وكيفية تطبيقها وبيان كيفية تشجيع القطاع الخاص لاستخدام المخلفات الزراعية في الانتاج وتحليل الجدوى الاقتصادية والبيئية لإدارة الدخلفات وتقييم العائد

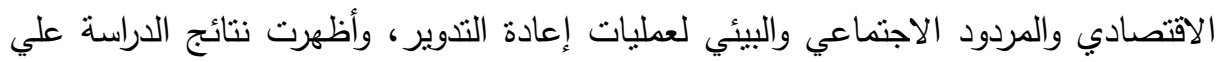

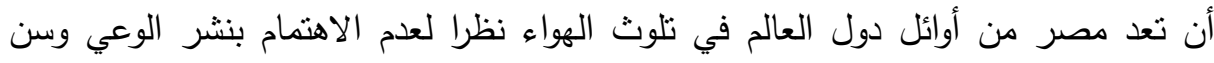

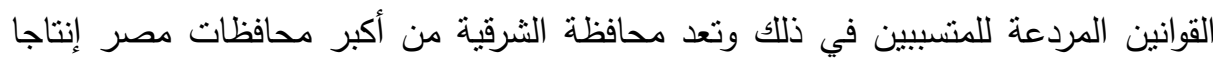
للأرز وبالتالي أكبر محافظة يتم فيها حرق قش الأرز ويواجه نطبيق نظام الادارة البيئية

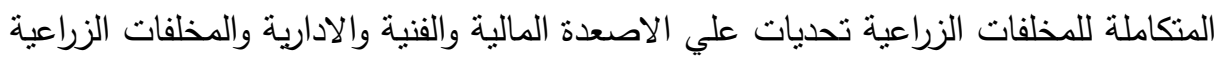
تمثل ثروة عظيمة لو أستغلها الانسان ولكن نقص الوعي يحولها إلي ضرر كبير يصعب الوبه

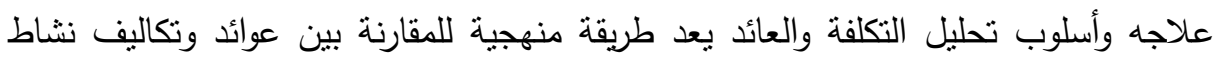
معين أو خدمة معينة وعند تطبيق أسلوب تحليل التكلفة والعائد علي الحالة التطبيقية التي استخدمت فش الأرز في إنتاج الغاز في الدقهلية تبين أن المشروع يحقق أرباح • استهدفت دراسة مني التعرف علي اقتصاديات تدوير النواتج الثانوية ومردودها البيئي والاجتماعي وذلك من خلال تحليل الطلب علي النواتج الثانوية ونسبة كل من الغير مستغل

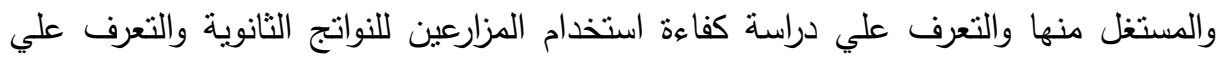

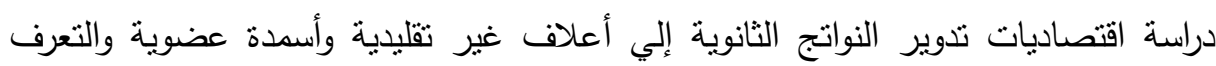

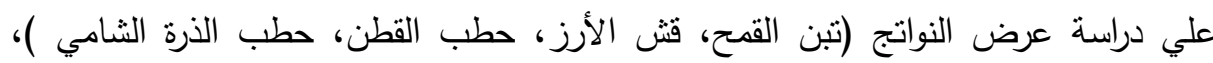

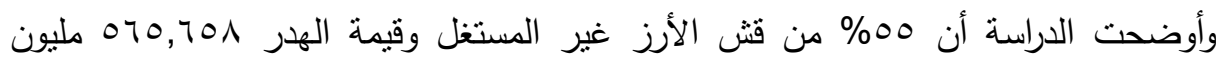

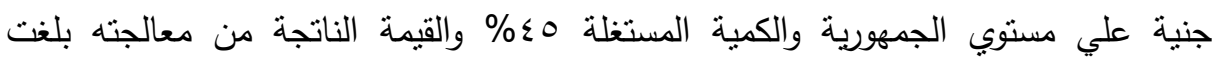

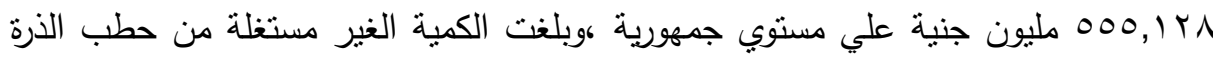




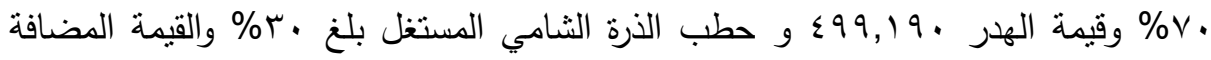

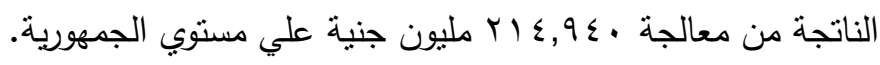

\section{إجباعاهت الهيهث}

وتم الاعتماد علي البيانات الجاهزة المتمثلة في تطور المساحة والانتاجية والانتاج لحبوب الأرز والفاقد منها و تطور الإنتاجية والإنتاج لقش الأرز، لذانية تم اختيار جمهورية

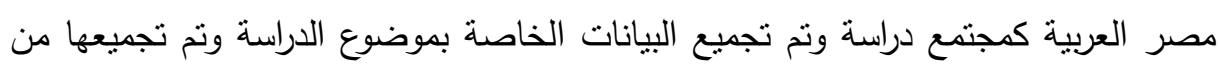

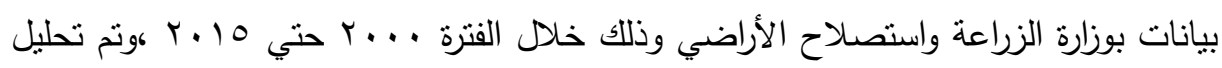

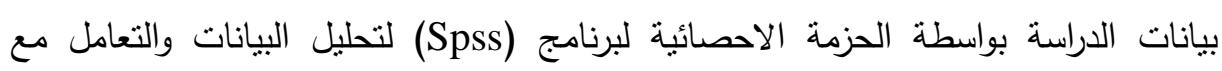
المتغيرات باستخدام الأساليب الاحصائية متل: معامل الارتباط البسيط لبيرسون لقياس قوة لإنهات الارتباط بين المتغير المستقل والتابع وبناء علي وجود ارتباط معنوي بين هذه المتغيرات بتم لإني

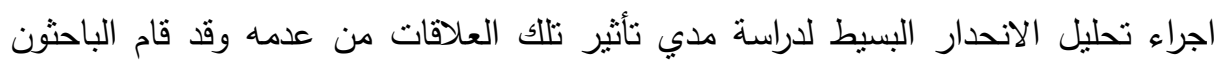

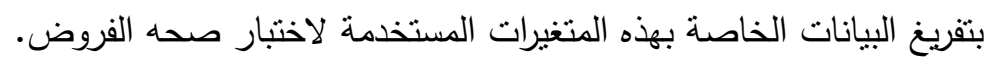

\section{نمأئج الترواسة}

اختبار صحة فروض البحث:

( ) متغيرات الاراسة

\begin{tabular}{|c|c|c|}
\hline المتغير & الرمز & \\
\hline 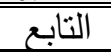 & $\overline{\mathrm{Y} 1}$ & إجمالى المساحة المقدرة المزروعة آرز بالالكف فدان \\
\hline التابع & $\mathrm{Y} 2$ & إجمالى الكمية التقديرية لإنتاجية الفدان من محصول الأرز طن/فدان \\
\hline التابع & Y3 & إجمالى الكمية التقديرية لإنتاج الأرز بالألف طن \\
\hline 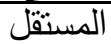 & $\mathrm{X} 2$ & الفاقد من الآرز \\
\hline 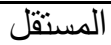 & $\mathrm{X} 1$ & 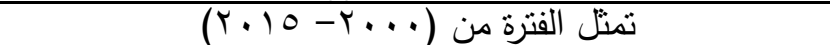 \\
\hline 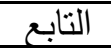 & Y5 & إجمالى الكمية التقديرية لإنتاجية الفدان من قش الأرز طن/فدان \\
\hline التابع & Y6 & إجمالى الكمية التقديرية لإتتاج قش الأرز بالآلف طن \\
\hline
\end{tabular}


( ا أثر المتغير المستقل علي المتغيرات التابعة: أ) المساحة في مصر (بالألف فداني)

\begin{tabular}{|c|c|c|c|c|c|c|}
\hline "ق" قيمة "F" & معامل التحديد & $\begin{array}{c}\text { الارتباط "معامل } \\
\text { Re }\end{array}$ & الدالة "Pستوي & "تيمة "ت "T" & المعلمة & المتغير \\
\hline \multirow{2}{*}{$\cdot, 079$} & \multirow{2}{*}{ •, זq. } & \multirow{2}{*}{$\cdot, 191$} & $r, \cdot 1$ & $19, .9 V$ & $10 Y 1, V$ & الثابت \\
\hline & & & $\cdot, \leqslant 7$ & $\cdot, V 0 \leqslant-$ & $7, Y)-$ & Y1 \\
\hline
\end{tabular}

(1)

$$
\begin{aligned}
& \text { ص^ه = } \\
& \text { *** ( , , } \vee 0 \leq-) \\
& \text {.,07q = ف } \\
& \text { حيث تشير : }
\end{aligned}
$$

صهـ : القيمة التقديرية لمساحة الأرز في مصر بالألف فدان خلال الفترة هـ

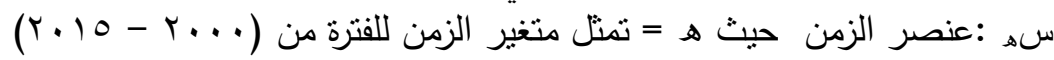

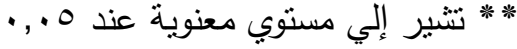

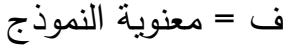

يتضح من دراسة المعادلة رقم (1) أن مساحة الأرز في مصر تنتاقص بمقدار بلغ

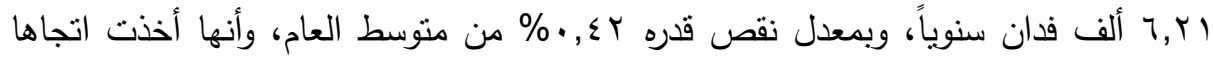

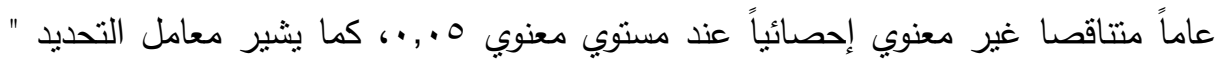

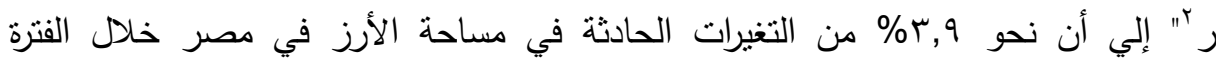

\begin{tabular}{|c|c|c|c|c|c|c|}
\hline "ق" قيمة "F" & $\begin{array}{l}\text { التحايد } \\
\text { "R2" }\end{array}$ & 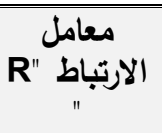 & "Pستوي & "قيمة "ت" & " المعلمة " & المتغير \\
\hline \multirow{2}{*}{$1, \varepsilon \pi r$} & \multirow{2}{*}{ •., } & \multirow{2}{*}{ o., } & $\left.V, \sum V\right\rceil$ & $r \cdot, 0 \leqslant r$ & $\varepsilon, Y \cdot r$ & الثابت \\
\hline & & & .,YO & $1,19 \vee-$ & ,, YOO & Y2 \\
\hline
\end{tabular}
موضوع الدراسة إنما ترجع للعوامل المسئول عنها الزمن والباقي وقدرة ا, 99\% إنما ترجع إلي

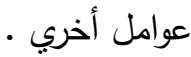

ب) الإنتاجية في مصر (طن/فران) جدول(ץ): يوضح نتائج تحليل الانحدار (الإنتاجية في مصر ) 
ص ص

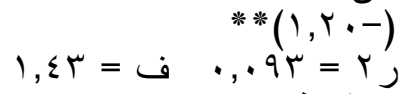

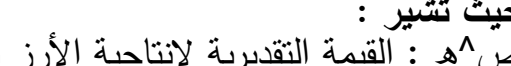

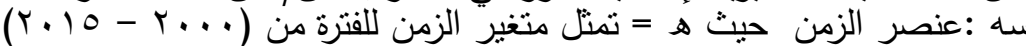

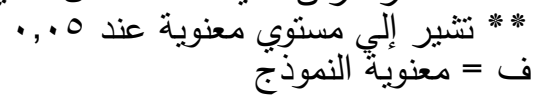

يتضح من دراسة المعادلة رقم (Y) أن إنتاجية الأرز في مصر تتتاقص بمقدار بلغ

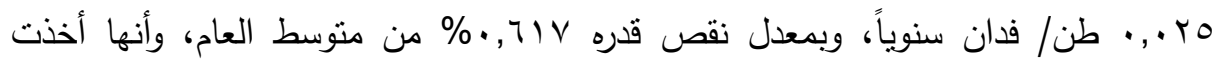

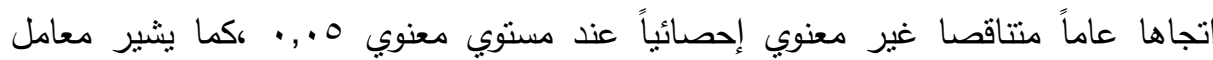

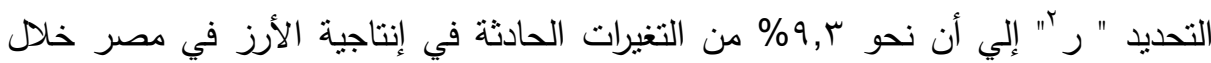
الفترة موضوع الدراسة إنما ترجع للعوامل المسئول عنها الزمن والباقي وقدرة >, >9\% إنما

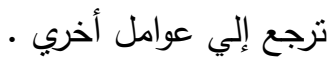

\begin{tabular}{|c|c|c|c|c|c|c|}
\hline قيمة "ق" ق" ق" & $\begin{array}{l}\text { التحعاملد" } \\
\text { "R2" }\end{array}$ & 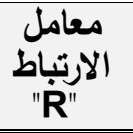 & "Pستوي & قيمة "ت" "T" & " المعلمة " & المتغير \\
\hline \multirow{2}{*}{$r, \varepsilon 0}$. & \multirow{2}{*}{$\cdot, 1 \leq 9$} & \multirow{2}{*}{$\cdot$, ז人ч } & $1,0 \leqslant \vee 9$ & $17, \varepsilon \cdot 0$ & $7 \Gamma \wedge 0, \leqslant Y 0$ & الثابت \\
\hline & & & $\cdot, 1 \leqslant$ & $1,070-$ & $7 r, .09-$ & Y3 \\
\hline
\end{tabular}

ت) الإنتاج في مصر (بالألف طن) جلول (r): يوضح نتائج تحليل الانحدار (الإنتاج في مصر )

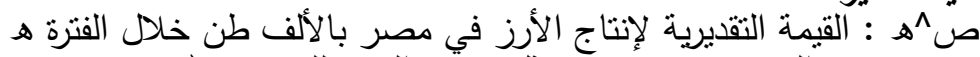

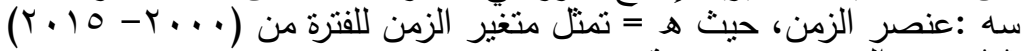

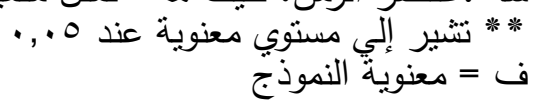




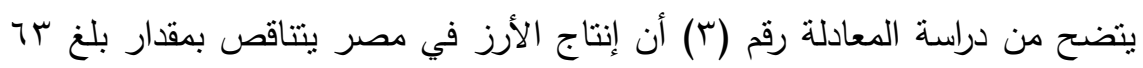
ألف طنسنوياً، وبمعدل نقص قره 1 • , 1\% من المتوسط العام ،وأنه أخذ اتجاها عاماً متتاقصا

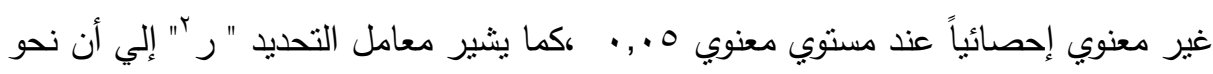

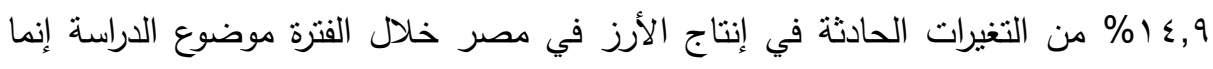

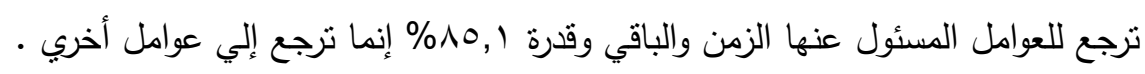
ث) (الفاق من حبوب الأرن (بالألف طن)

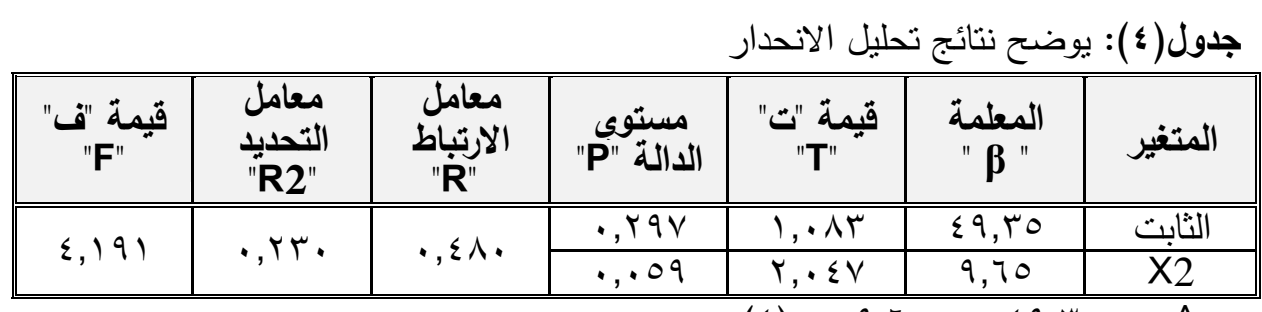

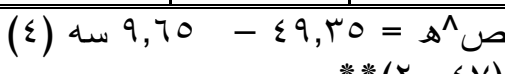
$\varepsilon, 19=\omega^{\prime} \cdot, r r \cdot=r$ J

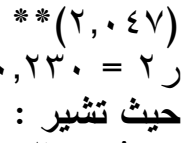

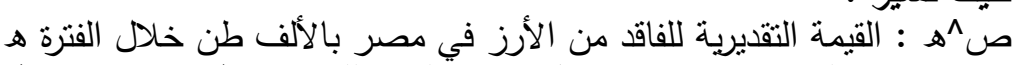

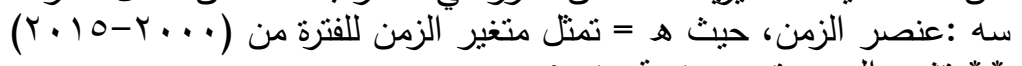

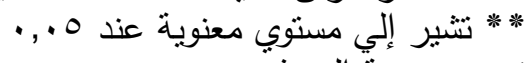
ف = معنوية النموذج منيج

ويتضح من دراسة المعادلة رقم (ع) أن الفاقد من الأرز في مصر يتزايد سنوياً خلال

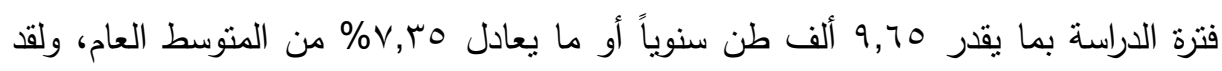

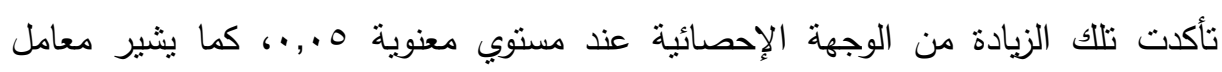

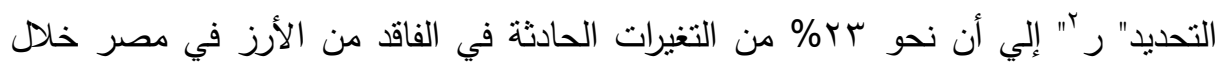

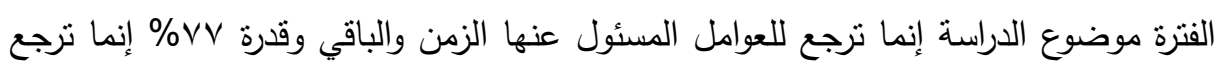

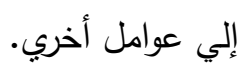


ج) الإنتاجية لقش الأن في مصر (طن/فـان) جدول(0): يوضح نتائج تحليل الانحدار

\begin{tabular}{|c|c|c|c|c|c|c|}
\hline قيمة" "ق" & $\begin{array}{c}\text { "التحديد"R2" } \\
\end{array}$ & الارتباط R R R & "مستوي & قيمة "ت" & " المعلمة & المتغير \\
\hline \multirow{2}{*}{$\cdot, r \leq r$} & \multirow{2}{*}{$\cdot, \cdot, V$} & \multirow{2}{*}{ וTו, • } & 9,90 & rq, rq & $r, 17 r$ & الثابت \\
\hline & & & $\cdot, 7 Y 9$ & $\cdot, \leq 9 \leq$ & $\cdot, \ldots Y \wedge$ & Y5 \\
\hline
\end{tabular}

$(0)$

$* *(\cdot, \leqslant 9)$

$\cdot, r \varepsilon=\omega \cdot \cdot \cdot 1 V=r$

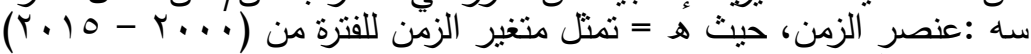
* * تشير إلي مسنوي معنوية عند 0 • , .

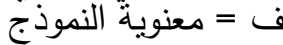

يتضح من دراسة المعادلة رقم (0) أن إنتاجية قن الأرز في مصر تنزايد سنوياً خلال

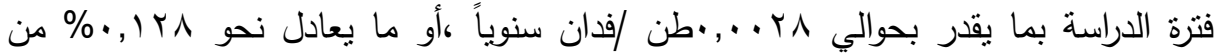

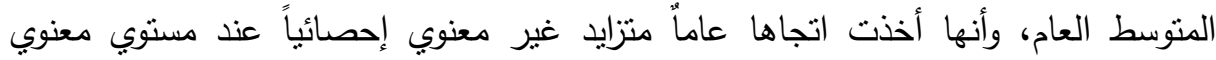

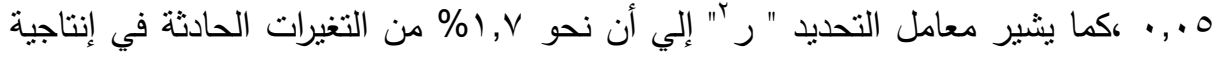
قش الأرز في مصر خلال الفترة موضوع الدراسة إنما ترجع للعوامل المسئول عنها الزمن

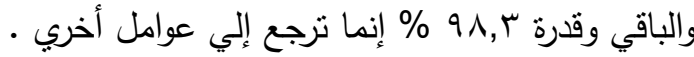
ح) الإنتاج لقش الأرن في مصر (بألف طن) جدول( ) : يوضح نتائج تحليل الانحدار

\begin{tabular}{|c|c|c|c|c|c|c|}
\hline "قيمة "ق" & $\begin{array}{l}\text { التحديد } \\
\text { "R2" }\end{array}$ & $\begin{array}{c}\text { الارتباط } \\
\text { "R" } \\
\text { "R" }\end{array}$ & "Pستوي & "T" قيمة "ت" & " المعلمة " & المتغير \\
\hline \multirow{2}{*}{ r,7דA } & \multirow{2}{*}{$\cdot, 17}$. & \multirow{2}{*}{$\cdot, \ldots \ldots$} & $\Lambda, r V$ & $I V, I V V$ & $r \leqslant \leqslant \Lambda, 70$ & الثابت \\
\hline & & & $\cdot, 1$ Yo & 1, 1, - & $r r, q 10-$ & Y6 \\
\hline
\end{tabular}


: حيث تشبر :

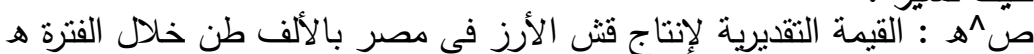

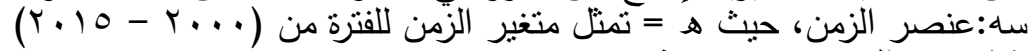
ف* *تير إلي مستوبي معنوية عند 0 •.

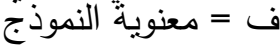

يتضح من دراسة المعادلة رقم (ך) أن إنتاج فش الأرز في مصر بيتاقص بمقدار بلغ 9, ب ألف طن سنوياً، وبمعدل نقص قدره 0 ., 1\% من متوسط العام ،وأنه أخذ اتجاها عاماً متتاقصا غير معنوي إحصائياً عند مستوي معنوي 0 ., • ،كما يشير معامل التحديد "رَ" إلي أن نحو 1 أ من التغيرات الحادثة في إنتاج فش الأرز في مصر خلال الفترة موضوع الدراسة إنما ترجع للعوامل المسئول عنها الزمن والباقي وقدرة عم \% إنما ترجع إلي عوامل أخري.

خ) العلاقة بين المساحة المزيوعة بالأنز بالألف فذان وكمبة الفاقد علي مستوي جمهوية مصر العربية جدل(V): يوضح نتائج تحليل الانحدار

\begin{tabular}{|c|c|c|c|c|c|c|}
\hline قيمة "ف" & $\begin{array}{l}\text { "التحعلد } \\
\text { "R2" } \\
\text { "R2" }\end{array}$ & الارتباط & "الدالة "Pستوي & قيمة "ت "T" & " المعطمة " & المتغير \\
\hline \multirow{2}{*}{1,179} & \multirow{2}{*}{ س •, } & \multirow{2}{*}{$\cdot, r \wedge \wedge$} & · $\cdot, \wedge) \wedge$ & ס & $19, \wedge \varepsilon$ & الثابتت \\
\hline & & & $\cdot, Y \wedge$. & $1,1 \times 7$ & $\cdot, \cdot 7 \varepsilon$ & Yं1 \\
\hline
\end{tabular}

( $* *(1,1, Y 7)$

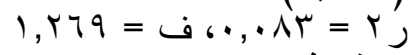
: حيث تشبير

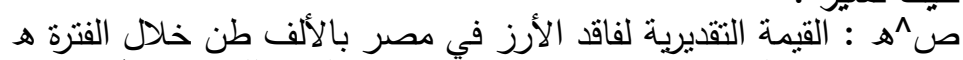

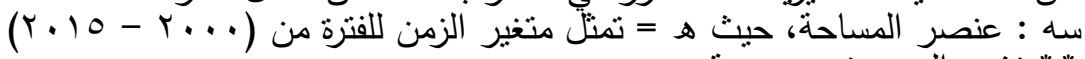

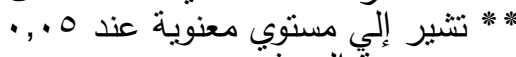

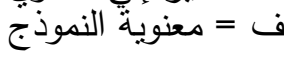

ويتضح من دراسة المعادلة رقم (V) أن الفاقد من الأرز في مصر يتزايد سنوياً خلال

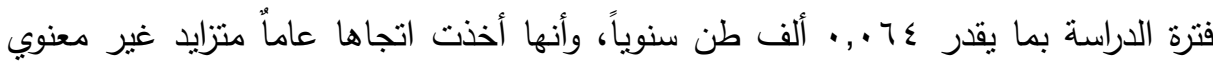

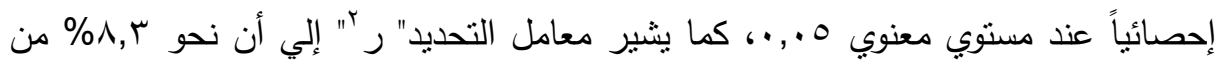

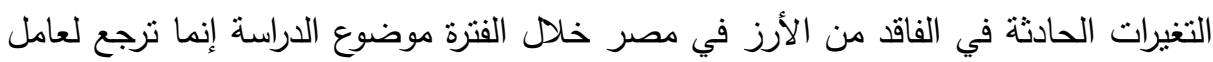

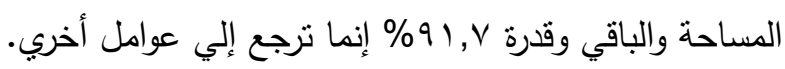
المجلد الواحد والاربعون، الجزء الأول، مارس^ا +. 
د) العلاقة بين الإنتاجية الفدانبة للأزن بالطن / فدان وكمبة الفاقد علي مستوي جمهورية

مصر العربية

جدول(^) يوضح نتائج تحليل الانحدار

\begin{tabular}{|c|c|c|c|c|c|c|}
\hline قيمة "قف" & $\begin{array}{l}\text { التحدايد } \\
\text { "R2" }\end{array}$ & $\begin{array}{l}\text { الارتباط } \\
\text { معامل } \\
\text { "R" }\end{array}$ & "الدالة "Pستوي & قيمة "ت & " المعلمة " & المتغير \\
\hline \multirow{2}{*}{$\varepsilon,|M|$} & \multirow{2}{*}{$\cdot, r Y \wedge$} & \multirow{2}{*}{$\cdot, \varepsilon \vee V$} & $\cdot, \ldots \varepsilon$ & $r, \leqslant 7 r$ & $\overline{T V O, T V T}$ & الثابت \\
\hline & & & $\cdot, \cdot 7 r$ & $r, \cdot T Y-$ & $\varepsilon \cdot, \Gamma\urcorner-$ & $\mathrm{Y} 2$ \\
\hline
\end{tabular}

صמ

$* *(r, \cdot r r-)$

$\varepsilon,|r|=\omega ، \cdot, r \Lambda=r\}$

صيه : القيمة التقديرية لفاقد الأرز في مصر بالألف طن خلال الفترة هـ

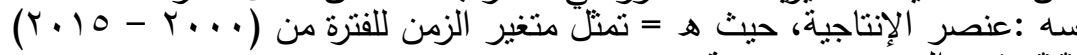

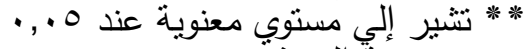

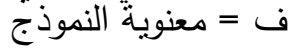

ويتضح من دراسة المعادلة رقم (^) أن الفاقد من الأرز في مصر يتتاقص سنوياً خلال

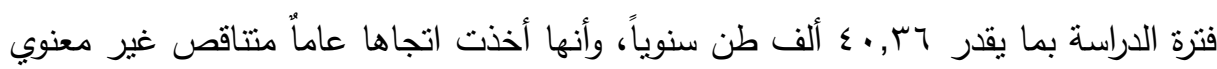

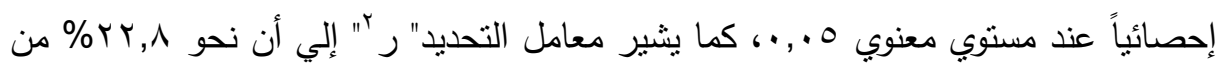

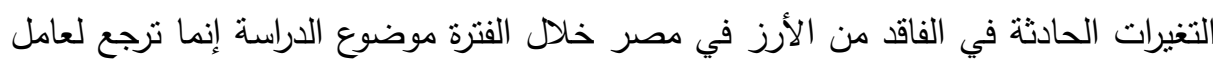
الإنتاجية والباقي وقدرة YVV, r إنما ترجع إلي عوامل أخري.

هـ) العلاقة بين كمبة الإنتاج من الأرن بالألف طن وكمبة الفاقد علي مستوي جمهورية

مصر العربية

جدول(9): بوضح نتائج تحليل الانحدار

\begin{tabular}{|c|c|c|c|c|c|c|}
\hline "ق" قيمة "F" & $\begin{array}{l}\text { التحايد } \\
\text { "R2" }\end{array}$ & 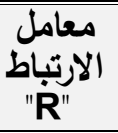 & " الدالة "مستوي & قيمة "ت" & " المعلمة " & المتغير \\
\hline \multirow{2}{*}{$\cdot, r \leqslant r$} & \multirow{2}{*}{$\cdot, \cdot r q$} & \multirow{2}{*}{$\cdot, 100$} & $\cdot, \cdot r \Lambda$ & $r, Y \wedge \Lambda$ & 10r,r74 & الثابت \\
\hline & & &., 077 & $\cdot, 0 \wedge 0-$ & $\cdot, \ldots V-$ & Y3 \\
\hline
\end{tabular}


مجلة العلوم البيئية

معهد الدراسات والبحوث البيئية - جامعة عين شمس لهن 


$$
\begin{aligned}
& \text { ص صه = } \\
& * *(\cdot, 0 \wedge 0-) \\
& \cdot r \leqslant r=\omega^{\prime} \cdot, \cdot r q=r ر
\end{aligned}
$$

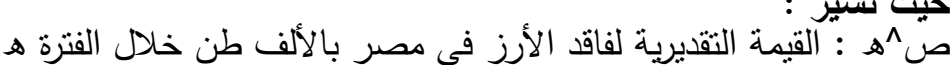

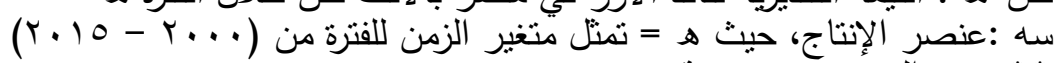

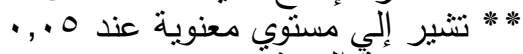

ويتضح من دراسة المعادلة رقم (9) أن الفاقد من الأرز في مصر يتتاقص سنوياً خلال

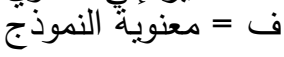

فترة الدراسة بما يقدر V . ., . ألف طن سنوياً، وأنها أخذت اتجاها عاماً منتاقص غير معنوي

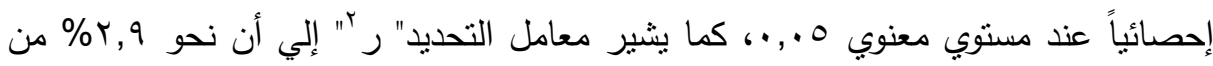

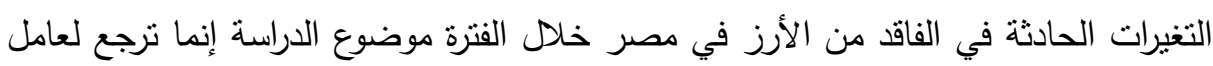
الإنتاج والباقي وقدرة و \% \% إنما ترجع إلي عوامل أخري.

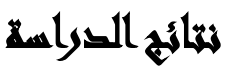

$$
\begin{aligned}
& \text { () نتاقص مساحة المزروعة من حبوب الأرز في مصر . } \\
& \text { r) تتاقص الإنتاجية الفدانية من حبوب الأرز في مصر؟ } \\
& \text { r) نتاقص الإنتاج الفداني من حبوب الأرز في مصر • } \\
& \text { ع) زيادة الفاقد من حبوب الأرز في مصر · } \\
& \text { 0) تتاقص الإنتاجية الفدانية من قش الأرز في مصر • } \\
& \text { 7) تتاقص الإنتاج الفداني من قش الأرز في مصر . }
\end{aligned}
$$

\section{الميوكيايت}

() فقد لوحظ صعوبة توصيف مشكلة الفاقد، حيث يثنرك العديد من المتغيرات مع بعضها لإحداث الفقد، حيث لا يوجد تعريف واضح وشامل للفاقدوجود التضارب بين المفاهيم المتعلقة بالفاقد أدى لصعوبة وضع طرق قياسية لتقديره، حيث لوحظ أن معظم الدراسات كانت تعتمد على تقديرات شخصيه من الباحثين ولذلك تخنلف منمنطقه لأخرى ومن بلد لآخري ومن باحث لآخر ولذلك نوصي بأن تتولي وزارة الزراعة بالتركيز علي قيام بأبحاث

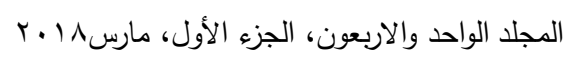


عن الفاقد الزراعي ووضع طرق قياسية دقيقة لتقديره وتوفير بيانات دقيقة للاعتماد عليها في علية تقدير الفاقد.

r) هناك زيادة في الفقد بسبب عدم قيام المنتجين الزراعيين علي القيام بفرز وتدريج وتعبئة

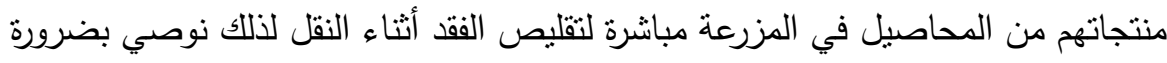

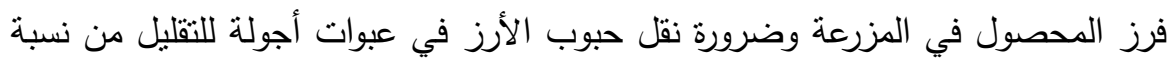
الفاقد.

r) أهية دور جهاز الدولة للشئون البيئية والتعاون مع وزارة الزراعة للاستفادة من النواتج الثانوية. §) ضرورة استخدام النواتج الثانوية لتوفير السماد العضوي وتوفير العلف لغذاء الحيوان وذلك للمساهمة في استصلاح الاراضي والتقليل من تكلفة الانتاج. 0) النواتج الثانوية تمثل ثروة اقتصادية عظيمة لذلك يجب استخدامها بشكل صحيح ولا يتم حرقها. 7) عدم وجود الاهتمام بالإجراءات والتكنولوجيا العلمية ذات صلة وتعزيزها للحد من الفقد الأرز ونواتجه الثانوية لذلك نوصي بالاهنمام بالتكنولوجيا العلمية ذات صله بله بالزراعة وضرورة نوفير آلات حديثة لحصد الأرز للتقليل من نسبة الفاقد من الأرز .

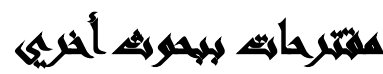

إجراء المزيد من الابحاث والدراسات علي موضوع الرسالة الحالية تتتاول الفاقد من

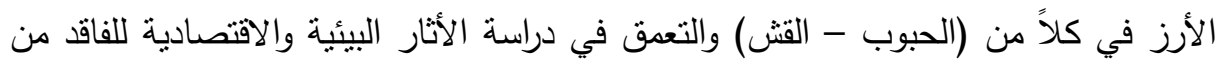

الأرز بوجه خاص والفاقد الزراعي بوجه عام لأهميته الاقتصادية والبيئية . 


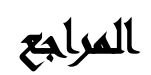

أحمد بكري عوض محمد(ب ( • ץ): "|قتصاديات تدوير المخلفات الزراعية النباتية وتأثنرها علي

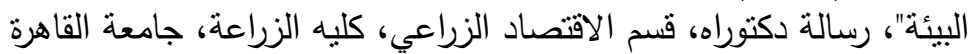

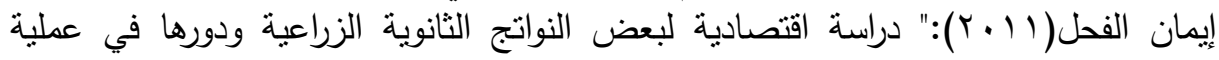

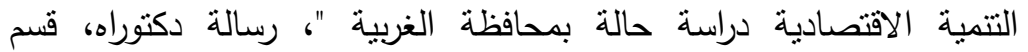

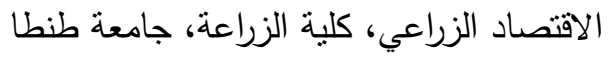

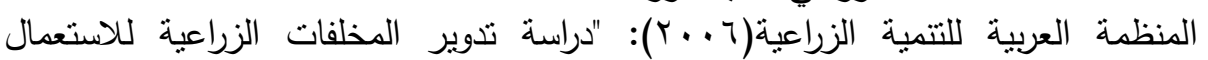

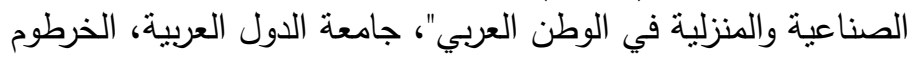

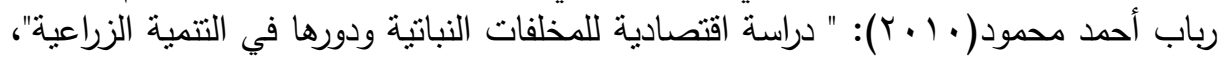

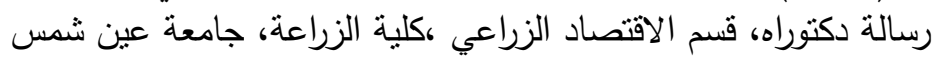

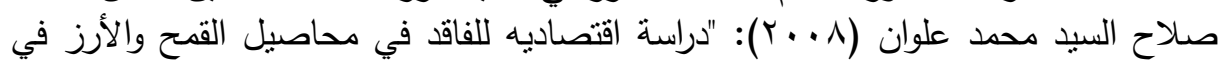
مرحلتي النقل والتخزين باستخدام اساليب معينه"، رسالة دكتوراه، قسم الاقتصاد الإداد

$$
\text { الزراعي، كليه الزراعة، جامعه القاهرة }
$$

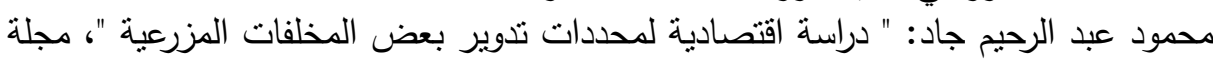

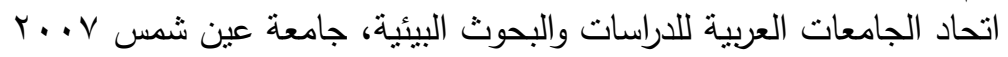

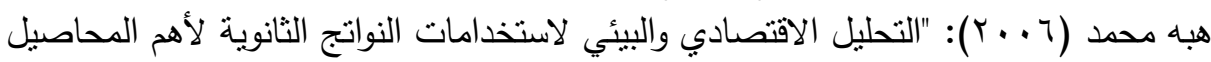

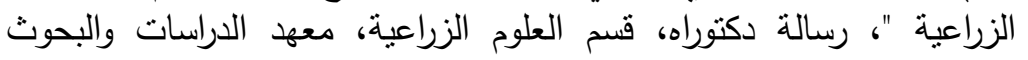

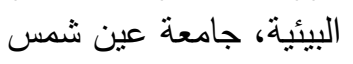

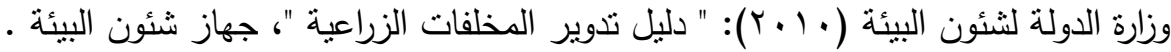

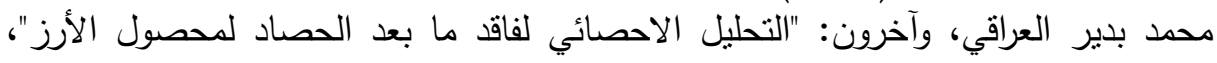

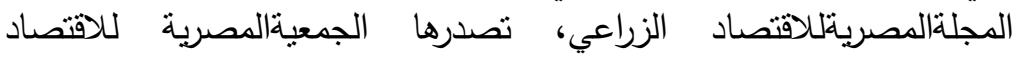

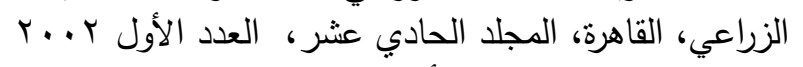

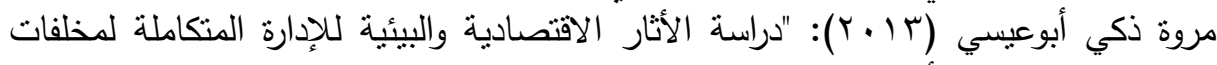

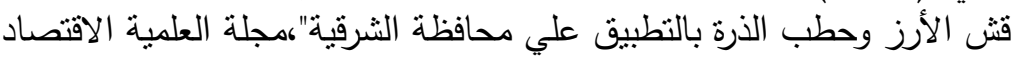

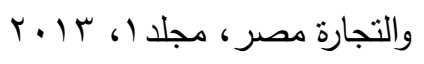

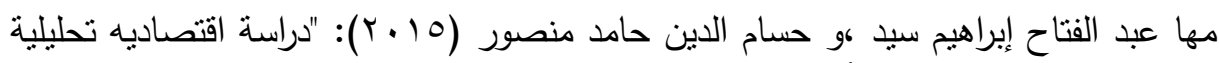

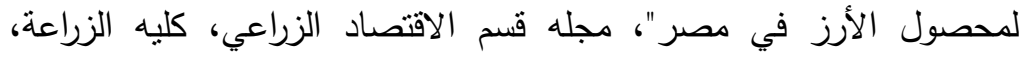

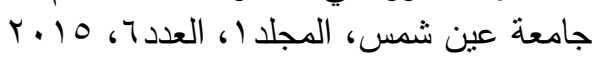

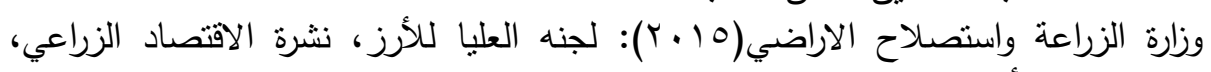

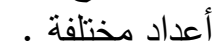

وزارة الزراعة واستصلاح الاراضي(10 ( ب): لجنه العليا للأرز، الفاقد في الأرز، نشرة الاقتصاد الزراعي، أعداد مختلفة الإنة

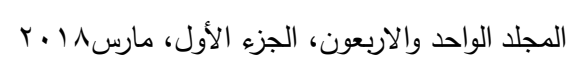


Abd El Mataleb; I.A. 1982 A Study on. The Optimum for Harvesting Rice and Wheat Crops by Small Harvesters M, Sc. Agric. Mech.; Dept. ,Fac. Agric. Univ. Tanta, 1982 .

Abd El Mataleb; I.A. 1982 A Study on. The Optimum for Harvesting Rice and Wheat Crops by Small Harvesters M, Sc. Agric. Mech.; Dept. ,Fac. Agric. Univ. Tanta, 1982.

Chazy ,E 1986 Utilization of Self Feeding Type Harvester and Reaper .The Field Practice of Mechanized Cultivation Training Text Book No. 1, Jica , RmpAmri/Arc. M.O.F. Cairo Egypt.

Ramos, B.M. 1982. An assessment of Rice Post Harvest Losses in Egypt Ricer Technology Training Center Alex .Egypt.

\title{
A STUDY ON THE ENVIRONMENTAL AND ECONOMIC EFFECTS OF LOSS OF RICE
}

Mandour, A. F. ${ }^{(1)}$; Abdel Hameed, Seham, A. ${ }^{(2)}$ and Salim, Aya, M. S.

1) Faculty of Commerce, Ain Shams University 2) Institute of Environmental Studies \& Research, Ain Shams University.

\begin{abstract}
The current study drives at identifying the environmental and economic impacts of rice loss. The analytical method is used to extract the research hypotheses and hypotheses will be tested through the analytical study on rice grains and the rice straw and their losses in the period 2000 to 2015. The development of area, productivity, and production of rice grain in Egypt are analyzed in the same period. Results of study indicate at testing hypotheses through the statistical analysis that the reddens (acre) area of rice in Egypt has decreased to 408

$$
\text { المجلد الواحد والاربعون، الجزء الأول، مارس^ا ـr }
$$
\end{abstract}


register $0.42 \%$ average annually. Productivity of rice grains in Egypt has decreased to represent $0.25 \%$ tons/per year with shortage rate $0.617 \%$ of year average. It is evident that rice production is decreasing annually with 63.000 tons/per year and shortness rate $1.08 \%$ of year average. The loss of rice grains has developed in Egypt to reach 9065 thousand tons annually i.e. $7.35 \%$ of the year average; taking into consideration that the price per one ton of rice grains in 2015 has been 3100 pounds. Regarding the productivity of rice straw, it is decreasing registering 0.0028 tons/per year and shortness rate $0.128 \%$ of year average. The rice straw production in Egypt is decreasing, registering 33.9 tons/per year and shortness rate $1.05 \%$ of year average; taking into consideration that the utilized amount of rice straw in Egypt represents $45 \%$ of the produced amount of the straw. Results conclude that there exists a significant statistical relationship between the cultivated area of rice and the amount of loss on the Republic of Egypt's level. The study recommends that Ministry of Agriculture should focus on establishing more research in agricultural loss, setting also a standard accurate approaches for estimating this loss and providing the necessary accurate data concerning the involved information of the loss estimation. There should be also coordination between Ministry of Agriculture and the State Agency for Environment Affairs to combat rice straw burning, moving and storing it instead to encourage investment in field of recycling rice straw.

Key Words: Rice grains - rice straw - loss of rice

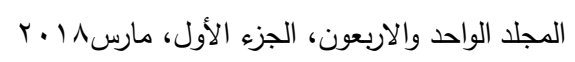

